\title{
Uma roda de rua: notas etnográficas da roda de capoeira de Caxias
}

\author{
Marcelo N. Almeida 1 \\ Tiago L. Bartholo 1 \\ Antonio J. Soares 1,2
}

https://doi.org/10.5628/rpcd.07.01.124

\author{
1 U niversidade Gama Filho \\ Brasil \\ 2 D epartamento de Educação Física \\ Universidade Federal do Espírito Santo \\ Brasil
}

\begin{abstract}
RESUMO
O objetivo do artigo é descrever, utilizando depoimentos dos fundadores e antigos freqüentadores, as memórias da "Roda de Capoeira de Caxias". Para isso, realiza uma pesquisa etnográfica durante o ano de 2003, objetivando entender como os atores sociais partilham a memória de umas das mais tradicionais e importantes rodas de capoeira do Brasil. O perfil do freqüentador atual da Roda de Caxias foi mapeado por meio de cinqüenta questionários respondidos por seus freqüentadores. O nascimento dessa roda de capoeira, na década de 1970, se tornou um modelo alternativo que, em certa medida, possibilitava a convivência, nem sempre pacífica, dos participantes e representantes das "escolas de capoeira" Angola e Regional.
\end{abstract}

Palavras-chave: capoeira, roda de Caxias, etnografia.

\begin{abstract}
Street capoeira: fieldnotes of the "Caxias roda de capoeira"

This paper aims at describing the memories of the "Caxias Roda de Capoeira" as they are presented in the testimonials of former founders and participants. In order to do so, we have carried an ethnographic research during the year of 2003 to understand how the social agents share their memories of one of the most traditional and important "rodas" de capoeira in Brazil. The profile of the current participant in the "Roda de Caxias" was mapped through the replies to fifty questionnaires applied among its frequenters. The appearance of this "roda de capoeira" in the 1970s was characterized as an alternative model, which to a certain extent, created conditions for the co-existence, not always pacific, among participants and representatives of the A ngola and Regional "capoeira schools".
\end{abstract}

Key-Words: capoeira, roda de Caxias, ethnography. 
O objetivo do artigo é descrever, utilizando depoimentos dos fundadores e antigos freqüentadores, as memórias da roda de capoeira de Caxias, a "Roda de Caxias". Para isso, realizamos uma pesquisa etnográfica durante o ano de 2003, objetivando entender como os atores sociais partilham a memória de umas das mais tradicionais e importantes rodas de capoeira do Brasil. ${ }^{1}$

Os instrumentos metodológicos utilizados no estudo foram a observação participante, as entrevistas e os questionários; o último foi aplicado para mapear o perfil socioeconômico dos freqüentadores da Roda de Caxias. Neste artigo, iremos privilegiar as entrevistas realizadas com os antigos participantes da roda, porém utilizaremos de forma pontual alguns dos dados colhidos dos questionários, quando corroborarem ou ilustrarem os argumentos. ${ }^{2}$

O trabalho de campo ocorreu de nove de março de 2003 até vinte e oito de dezembro do mesmo ano. ${ }^{3}$

Neste período os pesquisadores se inseriram no cotidiano da Roda de Caxias, de modo que passaram a freqüentar não apenas os momentos dos jogos de capoeira, como também, os encontros nos bares após as rodas, as confraternizações realizadas na cidade de Duque de Caxias e as festas particulares como aniversários ou festividades religiosas dos praticantes/informantes da Roda. A proximidade com alguns componentes da Roda de Caxias fora dos momentos de Roda/jogo foi fundamental na construção dos argumentos e das interpretações que apresentaremos a seguir.

$\mathrm{Na}$ observação participante foi construído um diário de campo, que teve como modelo o estudo realizado por Löic Waquant quando descreve o ambiente do Gym Box de Chicago - a dinâmica das relações sociais que se estabelecem entre os atores, assim como, as sensações vividas pelo pesquisador ao interagir com os lutadores (18).

De forma sintética podemos dividir os dados coletados em três tipos: a) dados coletados através de conversas e observações diretas com os jogadores da Roda de Caxias descritos nas notas do diário de campo; b) dados coletados nas entrevistas (formais) individuais ou em grupo; c) dados coletados através dos questionários distribuídos aos praticantes da Roda. O modelo de análise aqui empreendido parte dos seguintes princípios: a) não existe cultura pura ou em estado "puro", pois, toda cultura (no singular ou no plural) é híbrida e porosa aos contatos culturais. A cultura é um processo de simbolização coletiva em permanente construção, desconstrução e reconstrução, sendo simultaneamente reprodução e mudança. A mudança se expressa na permanente luta de afirmação de significados; b) entendemos que as identidades culturais se afirmam de forma relacional e situacional, a partir dessa concepção que se contrapõe a perspectiva metodológica da busca de atributos identificatórios, as identidades podem ser entendidas como segmentadas e/ou múltiplas. Os indivíduos e coletividades assumem determinada identidade a partir do que pensam de si em relação ao "outro" e a partir de como o "outro" os representa. Nessa direção, nos contrapomos as visões essencialistas de cultura e identidade ${ }^{(6,9)}$; c) a memória social é parte constitutiva do processo de construção e afirmação de identidades (15).

O perfil socioeconômico dos atuais praticantes da roda de capoeira de Caxias é bastante variado: jovens e idosos, semi-analfabetos e pós-graduados, abastados economicamente, desempregados, ex-presidiários, pessoas oriundas de diferentes pontos da cidade e até de outros países, tendo em comum uma mesma atividade e talvez buscando os mesmos objetivos na Roda de Caxias, isto é, o acúmulo de capital simbólico. O município de Duque de Caxias, localizado no Estado do Rio de Janeiro, Brasil, apesar de não ser identificado "no mapa cultural" da incipiente historiografia da capoeira como um local que auxiliou a formar tradição dessa prática corporal, teve suas ruas e praças como palco do nascimento e manutenção de uma roda de capoeira de rua que se mantém há mais de trinta anos. A Roda de Caxias, iniciada na década de 1970, surge da ruptura de um grupo de jovens praticantes do sistema que aqui chamaremos de capoeira esportiva. A capoeira praticada em academias de ginástica é nomeada, por alguns antigos freqüentadores da roda na linguagem nativa, como sistema acadêmico, aqui identificado de capoeira esportiva. Esse modelo parece ter uma estrutura semelhante às das artes marciais orientais, com uniformes, graduações e hierarquia, utilizando treinamento e disciplina esportiva. 
A Roda de Caxia que surgiu aparentemente sem grandes pretensões, se estabeleceu no decorrer dos anos de 1970 e 80, atraindo jogadores de inúmeras correntes da capoeira ${ }^{4}$ para as rodas que aconteciam nos fins de semana no município de Caxias. Muitos dos jovens jogadores que auxiliaram na instituição da Roda e muitos outros que se incorporaram ao grupo posteriormente tornaram-se expoentes da capoeira no Brasil e, conseqüentemente, em outros países. No decorrer deste artigo, alguns desses exfreqüentadores serão citados.

Não foi possível construir um mapa preciso dos primeiros jogadores de capoeira no município, porém os depoimentos convergem no sentido de apontar o Mestre Barbosa como precursor do ensino de capoeira em academias em Duque de Caxias. ${ }^{5}$ José Barbosa da Silva, o mestre Barbosa, nasceu no ano de 1946, em Pernambuco. Iniciou-se na capoeira no ano de 1962, em Recife, migrando para o Rio de Janeiro em 1965. Em 1971 fixou residência na Vila São Luiz, um bairro de Duque de Caxias. Começou ensinando capoeira na academia Líder, localizada no centro de Caxias - estabelecimento que permanece em funcionamento até os dias atuais. O grupo de mestre Barbosa chamava-se Grupo de Capoeira Zum Zum Zum. Nessa academia, treinaram alguns daqueles que ganharam prestígio e reconhecimento na Roda de Caxias. Como exemplo, podemos citar Marcos Antônio dos Santos (Marcão PQD), Ulisses Ribeiro de Sousa (Velho), Itamar da Silva Barbosa (Peixe), Luislan de Oliveira (Luizão) e Jonas Rabelo (Russo). Numa entrevista, realizada em 28 de dezembro de 2003, Mestre Barbosa respondeu o seguinte sobre as origens da capoeira em Caxias: "Q uem trouxe eu não posso te responder, mas quem organizou, uniformizou e produziu até hoje fui eu". A academia de Mestre Barbosa era filiada à Confederação Brasileira de Pugilismo e por isso usava um uniforme específico, calça esportiva e camisa de malha, ambas brancas. Também possuía um sistema de graduação chamado cordel. 6

Josias da Silva é outro mestre presente na memória da capoeira em Caxias. Segundo os depoimentos, seu trabalho é posterior ao de Mestre Barbosa. Mestre Josias, como é conhecido no município, pode ser identificado como um difusor de um estilo de capoeira esportiva. Ele fundou uma associação de capoeira que levava seu nome e sobrenome e dava aulas na Associação de Imprensa, localizada em um Shopping Center no centro de Caxias. Passaram por lá conhecidos nomes da Roda de Caxias, alguns se tornando destaques da capoeira: Jurandir Francisco Nascimento, Pedro Luís Soares Mello (Pedrinho de Caxias), Cinésio Feliciano Peçanha (Cobrinha Mansa), Welligton Rosa da Silva (Camaleão), Humberto Dantas Amaral (Baba) são alguns dos renomados ex-alunos de Mestre Josias.

Mesmo possuindo uma estrutura mais complexa, não foi essa capoeira sistematizada, praticada dentro das academias, que ficou marcada como a capoeira de Caxias, despertando a atenção de conhecidos praticantes de capoeira de várias partes do Rio de Janeiro, do Brasil e de outros países. Foi a capoeira praticada por alguns jovens em ruas e praças desse município que se configurou como uma espécie de "zona livre"7 da capoeira e, que a partir da década de 1970, atraiu jogadores de capoeira de várias partes do Estado do Rio de Janeiro e de diferentes estilos e escolas. 8

Segundo os depoimentos, a Roda de Caxias possui uma data precisa do seu surgimento, que é 13 de junho de 1973. Um grupo de jovens jogadores de capoeira, a maioria praticante de capoeira esportiva, se reuniu para fazer uma roda de capoeira dentro de uma festa na Igreja de Santo Antônio, localizada em Caxias. A partir da repercussão positiva dessa primeira roda, resolveram mantê-la semanalmente. Dentre esses jovens, estavam muitos praticantes que se tornaram famosos mestres da capoeira e continuam praticando até hoje, outros pararam ou faleceram. A primeira formação da roda era a seguinte: Jonas Rabelo (Mestre Russo9), Cinésio Feliciano Peçanha (Cobrinha Mansa), Itamar da Silva Barbosa (Peixe), Jurandir Francisco Nascimento (Jurandir), Paulo Ferreira (Paulo Brasa), Rogério Soares Peixoto (Rogério), Ulisses Ribeiro de Souza (Velho), Marcos Antônio dos Santos (Marcão PQD), Silves Luiz Francisco (Sílvio Azulão), José Iramar da Silva Barbosa (Popota), Ângelo Beatro (Julinho), Carlos Magno Ribeiro de Souza (Ninho), Anizia da Silva Barbosa, Jorge Luiz dos Santos (Gol). A maioria dos jogadores era adolescente na época da fundação. Os mais velhos, e que pareciam ser os articuladores da roda, eram Paulo Brasa, Rogério, Azulão e Russo. 
Esse núcleo, segundo depoimento de Mestre Russo, surgiu da dissidência das duas primeiras academias de capoeira de Caxias, a de Mestre Barbosa e a de Mestre Josias. Um grupo de alunos das duas academias, não satisfeito com aquele modelo de capoeira, resolveu buscar caminhos alternativos aos modelos vigentes. Vassalo descreve uma associação de capoeira parisiense chamada M aíra que, assim como a Roda de Caxias, surge da ruptura de um grupo de alunos com os modelos de capoeira implantados por mestres brasileiros em Paris (17). Segundo seus fundadores, todos franceses, esses modelos possuem uma organização social, extremamente rígida e hierarquizada. Parece ser a história dos jovens jogadores de Caxias se repetindo no Velho Continente.

Aqui devemos matizar o debate. A história sobre o surgimento da capoeira no Brasil ressalta a luta dos escravos contra o branco opressor. A capoeira assim é interpretada por parte da historiografia como um movimento de resistência contra a sociedade escravocrata. Essa discursividade heróica do oprimido versus o opressor também está presente na construção e consolidação da Roda de Caxias. Devemos enfatizar que a memória sobre a fundação da Roda, do ponto de vista nativo, reproduz os mitos presentes de uma "história heróica" da capoeira.

Em entrevista realizada com Mestre Russo, em sua casa, no dia 18 de dezembro de 2003, ele disse o seguinte a respeito do nascimento da Roda de Caxias:

N ós estávamos dentro de um sistema acadêmico10 mas estávamos buscando a capoeira em outros espaços... no dia 13 de Junho de 1973, quando nós ideal izamos uma roda dentro de uma feira católica, igreja de Santo A ntônio, resolveram manter esta roda. As coisas começaram a dar errado, mal compreendidos, e até hostilizados pelo sistema acadêmico. Passaram então a se dedicar ainda mais a roda que faziam aos domingos e aos treinamentos em quintais baldios para aprimoração da luta e união do grupo que estava sendo excluído naquele momento.

Após a primeira roda realizada pelo jovem grupo de jogadores de capoeira de Caxias, na Igreja de Santo Antônio, muitos deles ainda continuaram vinculados às suas respectivas academias por algum tempo, até que, em determinado momento, todos se desligaram de seus antigos mestres. Estar ligado à capoeira praticada nas academias era estar vinculado à capoeira estabelecida como produto no mercado dos esportes/atividade física. O discurso do rompimento é exaltado pelos pioneiros da Roda de Caxias, vista como um espaço alternativo. Eles deixam claro que agora passaram para o "outro lado da ponte" - exatamente como seus antepassados escravos, os jovens pioneiros da Roda de Caxias estavam à margem do sistema vigente.

O grupo passou, então, a realizar treinamentos em um terreno baldio onde anteriormente era local de ensaio de um bloco carnavalesco chamado Urro do Leão. Um dos fundadores da Roda, conhecido como Peixe, em 13 de Março de 2003, disse-nos o seguinte sobre como a Roda começou e os lugares por onde ela passou até os dias de hoje:

Ela começou lá na feira da comunidade, uma festa que tinha em Caxias que era da igreja. Botamos a primeira roda dentro da igreja, aí depois botaram a gente pra fora e a gente começou a fazer na Praça do R elógio, passamos um bom tempo lá mas depois começamos a ter problema com o comércio devido ao horário. Aí mudamos pra perto do Banco do Brasil. Depois passamos pra Praça do Pacificador. Sei que nós rodamos tudo. Também demos um intervalo que ficou um tempo sem ter roda, não sei se uns cinco anos. Foi porque dispersou os pessoal, dispersou, né? Só ficou eu e Russo aqui e não dava pra botar roda só os dois. Depois nós voltamos de novo na Praça do Pacificador de novo, ficamos e aí, então, Russo pediu opinião e resolvemos definir a roda aqui 11 e temos uns dois anos que estamos aqui.

Russo conta que o grupo passou a sofrer perseguições por membros da capoeira institucionalizada em academias, que viam na atitude tomada por aqueles jovens, uma afronta ao sistema vigente, tachando-os de marginais, alegando que prejudicavam a imagem da capoeira que, naquele momento, galgava um reconhecimento social que jamais tinha obtido. Interessante lembrar que as ruas de algumas Capitais brasileiras do período colonial são tidas como possíveis locais de nascimento dessa manifestação cultural (16). No entanto, a capoeira esportiva se contrapunha veementemente à capoeira praticada 
nas ruas e praças do município de Caxias, alegando que aquele tipo de roda manchava a imagem de uma ascendente e nova modalidade esportiva que buscava legitimidade social e reconhecimento nas organizações esportivas.

Aqui temos posto o debate de identidades contrapostas: aqueles que objetivavam uma maior organização e legitimidade da capoeira pelo sistema esportivo e pela sociedade e, em contraposição, aqueles que invocam o discurso de resgate da capoeira "original", da antiga técnica corporal criada pelos escravos. Se os primeiros buscam a legitimidade na expansão e criação de novos mercados para um produto que se valoriza não apenas internamente no Brasil, como também no exterior, os segundos capitalizam o discurso identitário de serem representantes/praticantes da "verdadeira capoeira". Todavia, a "verdadeira capoeira" também é um discurso presente no campo dessa prática corporal, que passa a ser uma moeda no mercado, tanto é assim que muitos daqueles que saíram de Caxias foram dar aulas e abrir academias no exterior - Estados Unidos e Europa - em nome da "verdadeira capoeira". O discurso identitário do tipo essencialista, independente da crença dos atores sociais, deve ser reconhecido como um forte argumento no mercado de produtos e serviços. Nossa sociedade se reencanta permanentemente nas diferentes narrativas que se baseiam na força simbólica da tradição, seja de caráter étnico, seja telúrico.

A Roda de Caxias foi se solidificando, porém continuou não sendo aceita, segundo os depoimentos colhidos, por alguns mestres da capoeira praticada em academias. Apesar de eventuais problemas, a roda foi ganhando fama e, nas décadas de 1970 e 80 , foi visitada e freqüentada por jogadores que hoje são reconhecidos no campo da capoeira. Nomes como Pedro Morais Trindade (Morais), ${ }^{12}$ José Tadeu Carneiro Cardoso (Camisa), 13 Sidney Gonçalves Freitas (Hulk), ${ }^{14}$ André Domingos (De Mola da Bahia), Sérgio Souza Oliveira (Nagô), Luís Malhado de Souza (Luís Malhado ou Luís Peito Pelado), Jair Moura, Mucungê, Waldenkolk Oliveira (Preguiça). Os depoimentos dos antigos freqüentadores da Roda de Caxias apontam Pedro Morais Trindade, conhecido na capoeira e reconhecido como Mestre Morais, como um dos principais incentivadores da Roda.
Morando em Duque de Caxias, Morais passou a visitar a Associação de Imprensa onde funcionava a Associação de Capoeira Josias da Silva e também o extinto Center Club de Caxias, local em que Mestre Barbosa coordenava a Associação de Capoeira Zum Zum Zum. Os dotes de Mestre Morais, como bom jogador de capoeira, são amplamente comentados por antigos freqüentadores da Roda. Seu estilo de jogo parece realmente ter impressionado os freqüentadores da Roda em seus primeiros anos, tanto que, dos dez fundadores da Roda de Caxias citados aqui, três passaram a treinar capoeira com ele, Cobrinha Mansa, Jurandir e Rogério.

Isaac Inácio da Silva, conhecido na capoeira como Mestre Angolinha, que se integrou à Roda de Caxias pouco depois de sua fundação e posteriormente tornou-se aluno de Mestre Morais, é um dos que comenta as muitas habilidades de Morais como jogador de capoeira. Segundo ele, o único jogador que conseguia enfrentá-lo de igual para igual num jogo de capoeira era Luís Malhado, ao qual se refere, quando argüido sobre quem era o melhor jogador que freqüentava a Roda de Caxias no passado. Vejamos este trecho de um depoimento dado por Angolinha, num bar no centro de Caxias, em 14 de março de 2004, logo após o término de uma das rodas dominicais:

A gora, bom que passou aqui na Roda de Caxias, foi Luís Malhado ou Luís Peito Pelado... Porque ele era bom mesmo, mandingueiro. $15 \mathrm{M}$ andingueiro! Principalmente ele jogando com M estre M orais, aí era jogo, jogo pra... $N$ ão tinha chance pra menino nenhum... Era o único do Rio que jogava que conseguia complicar o M orais no Jogo.

Mestre Peixe, um dos fundadores da Roda de Caxias que participava da entrevista citada, reforça as representações e lembranças sobre Luís Malhado afirmando: "R ealmente ele [ Luís M alhado] era um dos caras que eu também vi jogar, que vi complicar Morais". Mestre Morais tornou-se, segundo os depoimentos, uma espécie de parâmetro de qualidade de jogo na Roda de Caxias. O prestígio dos jogadores é sempre construído em comparação por aquilo que o grupo define e hierarquiza como competência. A memória oral dos entrevistados descreve/recorta estilos e façanhas dos jogadores que servem coletivamente como indi- 
cadores da qualidade do jogo. A transmissão oral dessas técnicas corporais, que possuem indivíduos como referentes, se apresenta como um campo de estudos fecundo para a pesquisa na Educação Física com interface nas Ciências Sociais.

Mestre Morais parece ser o grande responsável pela migração de vários jogadores de capoeira da Roda de Caxias, que não eram partícipes de nenhuma linha ou estilo específico de capoeira, para a Capoeira Angola. ${ }^{16}$ Alguns fizeram essa mudança diretamente por influência dele, outros se tornaram angoleiros incentivados por outros mestres da Angola e alguns se auto-intitulavam angoleiros sem dominar as técnicas corporais e os valores que os praticantes dessa vertente consideram tradicionais. A capoeira Angola se tornou um argumento de "identidade-para-o-mercado" que capitaliza a imagem de ser a "verdadeira" capoeira; ao mesmo tempo, torna-se uma prática alternativa à capoeira esportivizada que, segundo os angoleiros, perdeu suas raízes.

A Roda de Caxias, em seus primeiros anos, segundo o relato dos fundadores, sofria perseguições do sistema esportivo de capoeira, por isso possuía algumas estratégias de defesa, para dificultar possíveis investidas de seus antagonistas. Não podemos deixar de registrar que o discurso da perseguição e ameaça é uma tática discursiva de afirmação de identidade e coesão grupal. Uma dessas estratégias, por exemplo, segundo os depoentes, era não realizar a roda em locais de fácil acesso e próximos à principal entrada do município. Por isso as rodas aconteciam em locais em que visitantes que fossem até lá com o intuito de prejudicar a roda teriam dificuldade para fugir. Todavia, observemos que a roda era utilizada, por ser uma zona livre, também como local de emulação e encontro de diferentes estilos de capoeira. O fato de a roda acontecer na rua fez com que ela, independente das narrativas de perseguição, também estivesse sujeita a ter problemas com o comércio ambulante, com a polícia e até mesmo com outras manifestações populares, como a que ocorreu no carnaval de 1981, conforme comentário de Mestre Peixe:

Em 81, a gente tava fazendo uma roda de carnaval, ali na Presidente Kennedy do outro lado da rua ali, era terçafeira de carnaval, último dia de carnaval, a gente fazendo a roda, o bloco tentou invadir. Aí o finado Chiquinho não deixou os caras passar, aí o coro comeu, todo mundo apanhou, todo mundo bateu, até mestre $D$ entinho17 tava aí. Russo bateu pra caramba, apanhou também, nós perdemos nossos instrumentos tudinho, o único instrumento que se salvou foi atabaque, foi até minha esposa, que na época era minha namorada, que apanhou pra caramba mas conseguiu salvar 0 atabaque.

Esse acontecimento parece ter sido realmente marcante para os freqüentadores que estavam nessa roda. Isso pode ser observado no depoimento de outro fundador da Roda de Caxias, conhecido como Velho. Em uma entrevista realizada no dia 6 de maio de 2003, ao ser perguntado sobre qual foi o fato mais marcante que ele presenciou na Roda de Caxias, ele também respondeu que foi o incidente do carnaval de 1981 e disse o seguinte a respeito:

A roda que marcou foi uma do carnaval. Teve um tumulto e o pessoal do bloco das piranhas queria invadir a roda e a rapaziada não deixou, aí houve distúrbio, teve briga. Aí cada um foi pra um lado e a polícia foi atrás da gente perguntando: 'Cadê os capoeiras? Cadê os capoeiras?'... Tinham onze capoeiras contra quinhentos do bloco das piranhas. Foi o fato mais marcante da Roda de Caxias.

O confronto citado acima parece ter dado um sentido de coesão ao grupo. Pode-se perceber certo orgulho dos narradores por terem participado desse acontecimento, devido à forma entusiasmada como minudenciavam os fatos do dia do confronto, parecendo veteranos de guerra narrando uma batalha em que defendiam a soberania nacional.

Na década de 1990, a roda de Caxias parou por cinco anos em função, segundo os depoimentos, de seus principais organizadores viverem alguns problemas em suas vidas privadas, problemas esses que não foram revelados. Esse fato se apresenta como mais um dos indícios que fornece temas de estudo, para analisarmos como instituições dessa natureza se formam, se mantêm e desaparecem no tempo. A roda foi interrompida em 1993, voltando a ser realizada em 1998, por iniciativa de Mestre Russo que, como já foi mencionado, atualmente organiza os encontros da Roda de Caxias. 


\section{CONCLUSÃO}

A Roda de Caxias, segundo os depoimentos, continua à margem do circuito de uma capoeira esportiva e parece não ter interesse em participar dela, talvez pelo fato de que a maioria dos freqüentadores são vinculados à capoeira Angola, mesmo que alguns deles não definam um estilo no interior da roda. $\mathrm{O}$ discurso da Capoeira Angola é que sua técnica corporal se baseia mais numa prática cultural do que esportiva - observemos aqui que o cultural significa pureza, raiz e se transforma num discurso identitário essencialista. O esportivo já é encarado como artificial e como ruptura total com as "tradições da verdadeira capoeira". A capoeira esportivizada aqui existe apenas como "outro" necessário para afirmar as qualidades da capoeira Angola.

Todavia, não podemos esquecer que a Capoeira Angola não deixa de possuir um circuito de eventos, de rodas, sites de divulgação e ainda participar de um mercado de serviços que tenta atrair adeptos. Em contrapartida, é muito provável que discursos de capoeiristas vinculados a estilos mais esportivizados de capoeira construam narrativas identitárias com pequenas variações, se comparadas com o grupo estudado. Nesse caso, o "outro" pode estar mais fortemente ancorado naquilo que se define como não nacional, mas que foi incorporado e apropriado culturalmente. Em tese, poder-se-ia pensar que esses capoeiristas esportivizados afirmariam que a capoeira é o único esporte genuinamente nacional.

A capoeira jogada na Roda de Caxias se afirma em seu discurso identitário como resistente aos tipos de enquadramento presentes nos modelos sistematizados existentes no mercado. A Roda, mesmo após mais de trinta anos de sua instituição, é vista como um modelo alternativo de organização de capoeira, sem filiação, sem taxa de adesão e até mesmo sem uma rotulação específica quanto à capoeira jogada por lá. Noutra direção, a análise dos depoimentos pode apontar que a Roda se tornou um espaço de emulação de status entre os capoeiristas, entre estilos e se apresenta como um local de acúmulo de capital para participar no mercado da capoeira.

Nesse sentido, o prestígio acumulado pode servir como importante capital para a circulação do indivíduo no campo da capoeira, seja na memória dos praticantes, seja na afirmação existencial dos indiví- duos, seja, ainda, como meio de acesso para aqueles que desejam instituir seu próprio núcleo ou negócio. Isso não quer dizer, de maneira alguma, que os participantes entrem na Roda de Caxias com a intenção racional descrita por último. Todavia, as trajetórias dos capoeiristas relembradas pelos participantes da Roda de Caxias indicam que muitos abriram seus negócios e/ou formaram grupos no Brasil e no exterior. A Roda em questão ainda cria possibilidades, no mercado, de seus antigos freqüentadores e organizadores de ministrarem palestras e cursos.

No mercado da capoeira, a Roda de Caxias é um "celeiro de bambas" onde se joga a "verdadeira capoeira". ${ }^{18}$ Apesar de uma aparente informalidade e espontaneidade, a Roda possui uma prévia organização e uma estrutura que sobrevive há mais de três décadas. Embora a emulação de status não apareça em primeiro plano, a Roda possibilita visibilidade no campo. A experiência etnográfica na Roda de Caxias indicou que jogar capoeira nesse local parece servir como um rito de passagem do capoeirista, isto é, o bom capoeirista tem que se aventurar e testar suas técnicas corporais em Caxias. As pitorescas histórias, que circulam pela memória oral e são afirmadas como discurso identitário pelos participantes, parecem atrair jogadores e interessados de vários Estados e países. A Roda de Caxias se afirma como uma espécie de elo de ligação com a capoeira original ou primitiva que se torna uma obrigação para os jogadores que queiram se tornar "capoeiristas autênticos".

\section{CORRESPONDÊNCIA \\ Tiago Lisboa Bartholo}

Universidade Gama Filho

Programa de Pós-Graduação em Educação

Física/Brasil

Rua Viúva Lacerda 128/ apartamento 102, Humaitá CEP 22261050. Rio de Janeiro/ RJ, Brasil

e-mail: tbarthol081@ hotmail.com 


\section{REFERÊNCIAS}

1. Abreu F (2003). O Barracão do M estre Valdemar. Salvador: Zarabatana.

2. Almeida RC (1982). Bimba, perfil do mestre. Salvador: Centro Editorial e Didático da UFBA.

3. Archetti P (2003). Masculinidades: fútbol, tango y polo en la A rgentina. Buenos Aires: Antropofagia.

4. Capinussú JM (1989). A dministração e M arketing nas A cademias de Ginástica / José M aurício Capinussú, Lamartine Pereira da Costa. São Paulo: Ibrasa.

5. Clifford J (1998). Sobre a autoridade etnográfica. In: Clifford J. A experiência etnográfica: antropologia e literatura no século XX. Rio de Janeiro: Editora UFRJ, 17-62.

6. Cuche D (1999). A noção de cultura nas ciências sociais. São Paulo: EDUSC.

7. DaMatta R (1978). O ofício do etnólogo ou como ter 'anthropological blues'. In Nunes E (org). A aventura sociológica. Rio de Janeiro: Zahar, 23-35.

8. Geertz C (1997). "Do ponto de vista dos nativos": a natureza do entendimento antropológico. In: Geertz C. 0 saber local: novos ensaios em antropologia interpretativa. Petrópolis: Vozes, 85-107.

9. Kupper A (2002). Cultura: a visão dos antropólogos. Bauru: EDUSC

10. Lopes N (2003). Novo Dicionário Bantu do Brasil: contendo mais de duzentas propostas etmológicas acolhidas pelo dicionário H ouaiss. Rio de Janeiro: Pallas.

11. Oliveira RC (1998). O trabalho do antropólogo: olhar, ouvir, escrever. In: Oliveira, RC. 0 trabalho do antropólogo. São Paulo: Editora Unesp, 17-36.

12. Pastinha M (1988). Capoeira A ngola. Salvador: Fundação Cultural do Estado da Bahia.

13. Peirano M (1995). A favor da etnografia. Rio de Janeiro: Relume-Dumará.

14. Rego W (1968). Capoeira Angola: Ensaio Sócio - Etnográfico. Salvador: Editora Itapuã.

15. Santos MS (1998). Sobre a autonomia das novas identidades coletivas: alguns problemas teóricos. Revista Brasileira de Ciências Sociais 13(18): 151-165.

16. Soares CEL (1994). A N egregada Instituição: Os capoeiras no Rio de Janeiro. Rio de Janeiro: Secretaria Municipal de Cultura, departamento Geral de documentação e Informação Cultural, Divisão de Editoração.

17. Vassalo SP (2003). "Anarquismo, Igualitarismo e Libertação: A apropriação do jogo da capoeira por praticantes parisienses." In: XVII ENCONTRO ANUAL DA ANPOCS, Caxambú.

18. Wacquant L (2002). Corpo e Alma: Notas etnográficas de um aprendiz de boxe 
${ }^{1}$ Para um debate sobre as dificuldades e peculiaridades do trabalho etnográfico, ver: $(5,7,8,11,13)$.

2 Para mais informações sobre o questionário distribuído aos freqüentadores da Roda de Caxias ver Anexo 1.

3 O trabalho de campo aconteceu nos dias: $9 / 3,16 / 3,23 / 3,6 / 4$, $12 / 4,17 / 8,31 / 8,12 / 10,9 / 11,16 / 11,22 / 11,30 / 11,6 / 12$, 14/12, 21/12 e 28/12 do ano de 2003.

${ }^{4}$ Angola e Regional são os dois principais estilos de capoeira existentes. A Regional, que possui uma característica mais ofensiva, foi criada no início do século XX por Mestre Bimba (1). A capoeira Angola, que parece ter como características principais a ludicidade e tradicionalismo, teve em Mestre Pastinha seu maior incentivador e representante ${ }^{(12)}$.

${ }^{5}$ Vale lembrar que a capoeira passou a ser praticada em recintos fechados a partir de Mestre Bimba. O baiano Manoel dos Reis Machado, conhecido como Mestre Bimba, nasceu em 1889, foi o criador do estilo de capoeira regional (2). A academia de Mestre Bimba foi criada em 1932, sendo a quinta academia de atividade física do País (4).

${ }^{6} \mathrm{O}$ cordel ainda é muito utilizado em alguns grupos de capoeira da atualidade, é composto de fios de seda trançados com as cores da bandeira do Brasil para determinar o nível do praticante. Esse sistema foi criado em 1969, por Damionor Mendonça e apresentado em um simpósio no Campo dos Afonsos, no Rio de Janeiro, em plena ditadura militar quando a exaltação à Pátria e a seu pavilhão era um meio de propaganda utilizado pelas Forças Armadas.

7 "Zona livre" é um conceito que entende determinados espaços e objetos como menos afetados pelas restrições sociais que permitem a fruição da criatividade ${ }^{(3)}$. Esses espaços, segundo Archetti, seriam locais privilegiados para o observador social realizar suas interpretações.

8 Os estilos de capoeira devem aqui ser entendidos como formas distintas de uso do corpo no jogo de capoeira. É um discurso que marca a diferença perante o "outro". Não podemos esquecer que os estilos de capoeira se tornaram "marcas" no mercado nacional e internacional que podem ou não agregar valor ao "produto" oferecido pelo mestre em capoeira.

${ }^{9}$ Mestre Russo nasceu em 22 de setembro de1956, no Rio de Janeiro. Morador de Caxias desde a infância, foi lá que aprendeu capoeira com um primo conhecido como Crioulo. Em 1997, fundou o Grupo de Capoeira Cosmos. Atualmente coordena a Roda de Caxias e é um dos principais responsáveis pela sua continuidade.

${ }^{10}$ Quando Mestre Russo cita um sistema acadêmico de capoeira, ele está se referindo à capoeira praticada em academias e clubes com disciplina e treinamento esportivos que, em sua visão, seria um modelo antagônico ao da Roda em questão. ${ }^{11} \mathrm{Na}$ época em que este depoimento foi colhido, a Roda de Caxias acontecia no Calçadão do centro do município. Atualmente, ela retornou para Praça do Pacificador, também situada no centro de Caxias.
12 Baiano, oriundo de Ilha de Maré, Morais se iniciou na capoeira na cidade de Salvador, mudou-se para o Rio de Janeiro em 1970, fixando domicílio na Rua Tenente José Dias, no centro de Caxias. Mestre Morais, em 1981, fundou o G.C.A.P., Grupo de Capoeira Angola Pelourinho e foi o responsável pela revitalização da capoeira angola, que estava praticamente esquecida, ofuscada pelos holofotes que iluminavam a capoeira Regional praticada pelo Grupo Senzala, em franca ascensão a partir da década de 1970 .

${ }^{13}$ Mestre Camisa tornou-se um dos mestres de capoeira mais renomados da atualidade. Nascido na Bahia, mudou-se para o Rio de Janeiro na década de 1970, foi por alguns anos integrante do Grupo Senzala e posteriormente fundou a Associação Abadá-Capoeira. Segundo nossa experiência etnográfica, Mestre Camisa parece ser o precursor do estilo Capoeira Contemporânea.

${ }_{14}$ Mestre Hulk tornou-se campeão brasileiro de Vale-Tudo em 1995, vencendo um campeão de jiu-jitsu em pleno Maracanãzinho - estádio situado no complexo esportivo do Maracanã, que recebe esportes de quadra, como vôlei e basquete - no Rio de Janeiro.

${ }^{15}$ A expressão mandingueiro é muito utilizada por praticantes de capoeira para caracterizar um jogador malicioso que possua muita astúcia no jogo e que facilmente consiga ludibriar os adversários. O substantivo mandinga é oriundo de Mandinga, nome geográfico de uma região da África Ocidental conhecida por possuir excelentes feiticeiros ${ }^{(14)}$. O termo mandinga tornou-se sinônimo de feitiço e, conseqüentemente, mandingueiro de feiticeiro, porém, na capoeira, sua utilização não possui caráter religioso ou místico quando utilizado para caracterizar um jogador de capoeira.

${ }^{16}$ Capoeira Angola é um estilo que parece ser reconhecido pela maioria dos praticantes de capoeira como uma vertente mais tradicional. Os praticantes desse estilo se intitulam "angoleiros" e parecem acreditar ser esta mais pura e original, assim, mais próxima da capoeira que os escravos oriundos de Angola trouxeram da África. Portanto acreditam que a capoeira é uma manifestação africana e não brasileira. A escola mais famosa de Capoeira Angola é a de Mestre Pastinha e este parece ser considerado o seu maior representante.

17 Dentinho é um conhecido mestre de capoeira do Rio de Janeiro. Freqüentou a Roda de Caxias na década de 1970 e 1980. É morador da Penha, bairro situado na zona norte da cidade, onde parece ser muito popular. Segundo depoimentos, ficou afamado nas rodas de capoeira do subúrbio do Rio, por suas habilidades corporais e por seu excelente condicionamento físico. Dentinho é irmão de outro jogador de capoeira renomado, o Mestre Touro.

18 Bamba - palavra que vem de "mbamba", originária do dialeto africano quimbundo, significa pessoa que é autoridade em determinado assunto, mestre (10). 
Nome:

Nome de batismo na Capoeira:

Estado civil:

Idade:

Possui filhos:

Naturalidade:

Profissão:

Escolaridade:

Email:

Bairro onde reside:

Telefone:

1) Há quanto tempo pratica capoeira?

2) Você é professor de Capoeira?

3) É filiado a algum grupo ou associação de capoeira? Qual?

4) Há quanto tempo freqüenta a Roda de Caxias?

5) Com que freqüência você vai a Roda de Caxias?

6) Por que você freqüenta esta roda?

7) O que você apontaria como mais interessante nesta roda?

9) Você freqüenta outras rodas de capoeira além destas? Quais?

10) Qual tipo de transporte você utiliza para se locomover até a roda?

11) Pratica outra atividade física além da capoeira? 